\title{
Ronald W. Jones and Two-Sector Growth: Ramsey Optimality in the RSS and Leontief Cases
}

\author{
Minako Fujio ${ }^{\mathrm{a}^{* \dagger}}$ and M. Ali Khan ${ }^{\mathrm{b}^{*}}$ \\ a Otaru University of Commerce, Hokkaido, Japan \\ ${ }^{b} J o h n s$ Hopkins University, Baltimore, MD 21218, USA
}

\begin{abstract}
In this essay, we interpret the value-loss line, familiar in models of undiscounted optimal growth, as delineating the cone of diversification, familiar in models of international trade. This interpretation allows an embedding of the 2-sector Robinson-Solow-Srinivasan (RSS) model in the 2-sector Leontief model, and clarifies situations when the Leontief case offers additional insights into transition dynamics. The geometry underlying this embedding extends an earlier construction due to Khan-Mitra, and it has independent interest.
\end{abstract}

JEL Classification: D90, C62, O21

Keywords: factor intensities, cone of diversification, Brock prices, cyclicity

"Let no one who is ignorant of geometry enter here."

(Plato's Academy) ${ }^{1}$

* This paper is based on a talk given by the second author at the 2006 APJAE Symposium on International Trade in honor of Professor Ronald Jones. Khan-Mitra (2006a) was circulated as a background paper. He is grateful to the Department of Economics and Finance at City University of Hong Kong for its invitation and hospitality, and to Kenneth Chan, Jai-Young Choi, Ron Jones, Carsten Kowalczyk, Sugata Marjit, Kazuo Nishimura, Ray Reizman and Eden Yu for stimulating discussion on issues treated herein. This final version was written up when Khan was visiting the Department of Economics at Cornell during June 2006, he is grateful to the CAE for research support, and to Arnab Basu, Nancy Chau and Mukul Majumdar for stimulating discussion. The authors' dependence on Tapan Mitra regarding the material reported here goes beyond an acknowledgement.

${ }^{\dagger}$ Email address: fujio@ res.otaru-uc.ac.jp.

- Email address: akhan@jhu.edu.

${ }^{1}$ See, for example, D. F. Wallace, 2003, Everything and More, p 59, or R. Goldstein, 2005, Incompleteness, p 62, both published by W.W. Norton, New York. There is discrepancy between the two translations furnished there; we somewhat arbitrarily go with the first and leave a nicer resolution to those with a better classical education. 
“The number 'two' is undoubtedly encountered more frequently in the theory of international trade than in any other field of economics. It is a large number ..."

(Ron Jones, 1976) ${ }^{2}$

"The two-sector growth story is not for the squeamish."

(Amartya Sen, 1970) ${ }^{3}$

\section{Introduction ${ }^{4}$}

In a recent interview, ${ }^{5}$ Ron Jones was asked to comment on the fact that he thinks "very visually, much more than most economists." The interviewer, Vikas Kakkar, continued, "In your research and teaching, you use a lot of diagrams. In one graduate class, you drew forty-five diagrams in less than two hours!" Jones's response is instructive and worth pondering ${ }^{6}$ at some length.

"Well, I've often been accused of being much more interested in diagrams than algebra. But there's a reason for that. One of your basic questions in international trade is, 'What is the effect of moving from autarky to free trade?' That's a finite change-your calculus is not helping you at that stage, so that drawing pictures of the trading situation, comparing it with autarky etc is a very natural thing to do. And working with the two-sector model, and also with box diagrams, that was relatively new stuff. Things like factor intensity reversalyou really have to see what it is in order to play with that, and that was part of my dissertation. And trade uses small scale general equilibrium models so that they lend themselves pretty well to diagrammatic devices. And sometime in 1957, Tjalling Koopmans makes the remark that the eye is an organ of perception, not of reasoning. And I thought to myself as I read that 'Why is it when I finally understand something I say, "Gee, now I see!”

\footnotetext{
${ }^{2}$ See R. W. Jones, 1979, International Trade: Essays in Theory, (North Holland Publishing Co, Amsterdam) p 289.

${ }^{3}$ See A. K. Sen (ed.), 1970, Growth Economics, (Penguin Books, Harmondsworth) p 30. We are grateful to Debraj Ray for drawing our attention to this sentence.

${ }^{4}$ Primary responsibility for all non-scientific claims in this section, and in the rest of this essay, lies with the second author; all non-measurable, non-verifiable and non-objective extravagances are his.

${ }^{5}$ See City Economist Vol. 13, No. 1, November 2003. In Jones's response that follows, we excise parts of it after the sixth sentence and rearrange the seventh sentence. For two opposing points of view to geometry, see, for example, Kurz (1970) and Shackle (1956).

${ }^{6}$ This word has its own genealogy in the present context. It was used by Ethier (1993) and singled out in Khan's 1993 comment on Ron Jones's 1993 Quaid-e-Azam Lecture given to the PSDE: In this comment, Khan elaborates on the phrase artistic standard in Ethier's statement that "Jones has pondered almost every significant issue addressed by trade theory. Very often his treatment has been definitive; invariably it has set the artistic standard."
} 
In this essay for a symposium devoted to Ron Jones's work, we shall resist the linguistic and epistemological pull of this text: its juxtaposition of diagrams with algebra, ${ }^{7}$ its clarity regarding the basic, the slippage from algebra to calculus, its ease with a representation of a situation, be it pictorial or symbolic, its firm identification of the natural, the new versus the old, its reification of factor intensity reversals, perhaps even of autarky, the importance it gives to sight, to seeing finite, as opposed to infinitesimal, changes, seeing theorizing as play, a diagram as a device, its sensitivity to scale, its distinction of reasoning and perception, the eye and the mind. There is certainly a lot to ponder here, but instead, we shall address ourselves to an estrangement, the parting of ways between the theory of international trade and the theory of economic growth, at least as these theories are articulated in the older, classical literature. ${ }^{8}$ The new trade theory, at least from the outside, seems to be much more attuned to game theory and the new $I O$, and the new, endogenous growth theory, increasingly finds its habitual dwelling more in the domain of representative-agent macroeconomics than in any other.

But of course, it was not always so. The last three sections of Jones (1965a) concern themselves with "convergence to balanced growth," to "savings behaviour" and to the "analysis of technological change," and at least 12 out of its 25 references concern papers on economic growth, the first reference being Amano's 1963 dissertation on Neoclassical Models of International Trade and Economic Growth. In the first of the six paragraphs of Section 7, Jones writes:

\begin{abstract}
"The two-sector model of production described in Sections 1-6 can be used to analyze the process of economic growth. Already I have spoken of increases in factor endowments and the consequent 'growth' of outputs. But a more satisfactory growth model would allow for the growth of at least one factor of production to be determined by the system rather than given parametrically. Let the factor 'capital' replace 'land' as the second factor in the two-sector model. And let $M$ stand for machines rather then manufacturing goods. To simplify, I assume capital does not depreciate. The new feedback element in the system is that the rate of increase of the capital stock, $\hat{K}$ depends on the current output of machines, $M$. Thus $\hat{K}=M / K$. The 'demand' for $M$ now represents savings.”
\end{abstract}

The second paragraph explicates the term "balanced growth" and our essay can be seen, at one level, as a re-reading, some 40 years later, of the subsequent two paragraphs. For reasons of space, we shall just collapse them into two sentences, one composite sentence for each composed paragraph.

\footnotetext{
${ }^{7}$ Since this essay is not unconcerned with the history of economic thought, with economists as well as the economy, it is worth noting that 1961-62, 1977 and 1993 constitute three points of intensity reversals: Jones (1961), Brown-Jones (1962) to Jones-Scheinkman (1977) to Jones-Mitra (1993), Jones-Marjit-Mitra (1993). Perhaps Jones-Mitra (1999) can be ascribed to a publication lag to preserve the typology.

${ }^{8}$ It is easiest to designate the literature we have in mind by reference to the classic texts of Kemp (1969), Morishima (1969), Findlay (1970), Wan (1971) and Caves-Jones (1971).
} 


\begin{abstract}
"If machines are produced by labor-intensive techniques ... the economy tends toward the balanced-growth path. The difficulty arises if machines are capital-intensive [but] once account is taken of price changes, the change in the composition of outputs may be sufficiently damped to allow convergence to balanced growth."
\end{abstract}

The remaining two paragraphs of Jones's Section 7 make precise this "sufficiency" in terms of the concept of an aggregate elasticity of substitution.

But this re-reading of some sentences of a classic paper already pushes us further into the substance of this essay when the motivational task of its introduction remains yet to be completed. This, in a phrase, is simply an attempt to accentuate the importance of simplicity in the pursuit of the essential. ${ }^{9}$ Ruffin-Jones (2003) allude to this attitude, the fecundity of the analytical style that it carries with it.

\title{
"Simple examples often do much to reveal the essence of an argument without the need to follow the more elaborate reasoning required for the general case."
}

To return then to the estrangement of trade and growth theory,,$^{10}$ and without going into a detailed consideration of the history of this disciplinary re-situation and re-identification, one can perhaps see it reflected, at least as a first iteration, in the primitive dissonance between diagrams and algebra: as growth theory moved from descriptive to optimum growth, to the description of the optimizing behavior of a representative agent, and trade theory moved to the indeterminacies of game theory, the non-existent breach between Jones' hat-calculus and calculus had now to contend with a continuum of commodities or of types or of information, and correspondingly with variational calculus. ${ }^{11}$ A clutter of geometry is quickly revealed to be what it is - a clutter, but other than in the hands of a master, a clutter of symbols can easily slip into an awe-struck admiration of the exotic and the exoteric. Geometry thus keeps control on the substance of the investigation, keeps one on a straight substantive path, prevents one from clinging to scaffoldings, so to speak. ${ }^{12}$

Once geometry and simplicity are brought into the picture, it is difficult to resist mentioning another, perhaps more irreconciliable, estrangement also rooted in style and attitude: that between general equilibrium and trade theory. International trade theorists, more so

\footnotetext{
${ }^{9}$ In the second author's presentation in Hong Kong, Ron Jones pointed out the number of times the word "simple" had been mentioned. This is a second instance where his cursory remarks have led to a paper; for the first, though non-collaborative, instance, see Jones (1993).

${ }^{10}$ It bears emphasis that there have been attempts to patch this estrangement, as in Chipman-Inoue (2001), but they have been against the grain, and few and far-between.

${ }^{11}$ There is a reference to Caratheodory's book on the calculus of variations in the Collected Essays, see Jones (1979), pp 115, 125, referred to in note 2 above.

${ }^{12}$ The "scaffoldings" phrase is taken from the last response of Jones in the interview referred to in note 5 above. Over the years, the second author has found technically advanced students to be most resistant to the 2-sector model, and find difficulty in appreciating that it is not simply a "special case of the Arrow-Debreu model!" - for one thing, the prices of all commodities are given in the chapter on production in the Theory of Value. But see Khan (1993) for an attempt to discern a commonality of style between Debreu and Jones.
} 
than other economists, and perhaps not unlike their fellow-workers in dynamical systems, have not hankered after generality for its own sake, and have been entirely at ease with simple particular models. Jones (1956) concludes his very first paper with the following remark.

\section{"Finally, taking into account differences in technology or quality of the factors of production well as endowment proportions makes for sterile analysis, as trading patterns could then be explained by differences in factor endowments, or in the quality of the factors, or in technology or in conditions of demand."}

This sensitivity to sterility in a concurrent striving for simplicity, a contentment with caricatures, indeed a partiality to toy-models to make a point, has been at odds with the attitudes, and at times generalizations and pretensions, of so-called "high-brow" general equilibrium theory. ${ }^{13}$ But leaving general equilibrium theory aside, one can possibly say that with the parting of ways between trade and growth theory, gains from exchange and joint enterprise remain unrealized, and pioneering analyses, not only of Jones, but of Srinivasan (1962, 1964), Uzawa (1964), Shell (1967) and Haque (1970) have been left by the wayside. It is not surprising then that the two-sector model does not merit a chapter in texts of either the new growth theory, or in treatments of growth in texts of overlapping or single representative-agent macroeconomics. ${ }^{14}$

In this short essay, rather than a comprehensive documentation of ongoing work in growth theory in terms of the RSS and Leontief 2-sector models, we put out a pointer to serve as an instrument of reconciliation between classical trade and growth theory. This is the notion of the substitution of golden-rule or Brock prices for international commodity prices. Such a pointer not only avoids the continuum as much as possible by sticking to discrete finite changes, in time and in techniques, but gives the notion of relative factor intensities, and the resulting "cone of diversification," the primacy that it warrants, as in Jones's 2002 retrospective evaluation, and what, in the words of Solow (1961), appears only to be a "casual property of technology." And in terms of language and method, it does so in terms of Jones's classic articles and diagrams of 1965, along with those of HarrodJohnson and Woodland-Mussa. Ruffin-Jones (2003) follow their valorization of simplicity by the remark that it has "relevance for the effect of trade on real wages," and this essay then, is an attempt to substantiate its relevance also for the charting of optimal transition dynamics in the 2-sector neoclassical model. In particular, it leads us to ask when the simpler RSS model can be embedded in the Leontief model, and execute an answer through the value-loss line: the cone of diversification embodying relative factor intensities. However, as alluded to in the conclusion to this essay, an appreciation of the horizon that was being addressed in the six paragraphs of Jones (1965) referred to above, and the style and attitude to economic theory that it underscores, may perhaps be more important than any particular result.

\footnotetext{
${ }^{13}$ Hahn (1965) is perhaps the last general equilibrium monitoring of the 2-sector model.

${ }^{14}$ See, for example, Aghion-Howitt (1998) or the reader's favorite macroeconomics text.
} 


\section{The 2-Sector RSS Model: A Recapitulation}

The RSS model takes its name from pioneering work of Robinson, Solow and Srinivasan, ${ }^{15}$ and since its 2 -sector specialization has already been extensively presented elsewhere, we can be correspondingly brief.

In terminology popular with trade theorists, the 2-sector RSS model can be seen most easily as a Ricardian (machine-producing) sector coupled with a Leontief (consumption good) sector, with perfectly-divisible labor the common, stationary, factor and perfectlydivisible machines not being used in the production of machines. ${ }^{16}$ Unlike Jones (1965a), we shall assume an exponential depreciation rate parametrized by $d$, $0<d<1$, and rather than a savings function of the Cambridge variety, as in Jones (1965a, Section 8), an infinitely-lived representative agent, or better still, a Ramseyian planner. With the labor stock, the technological coefficients in the consumption goods sector, and the coefficients of the linear felicity function all normalized to be unity, the 2-sector RSS model can be represented by the triple $(a, d, \rho), a>0$ being the amount of labor used to produce a single machine and $\rho, 0<\rho \leq 1$, being the discount factor. In the undiscounted setting, where $\rho=1$, the model simply reduces to the pair $(a, d)$.

Figure 1: Basic Geometrical Benchmarks of the 2-Sector RSS Model

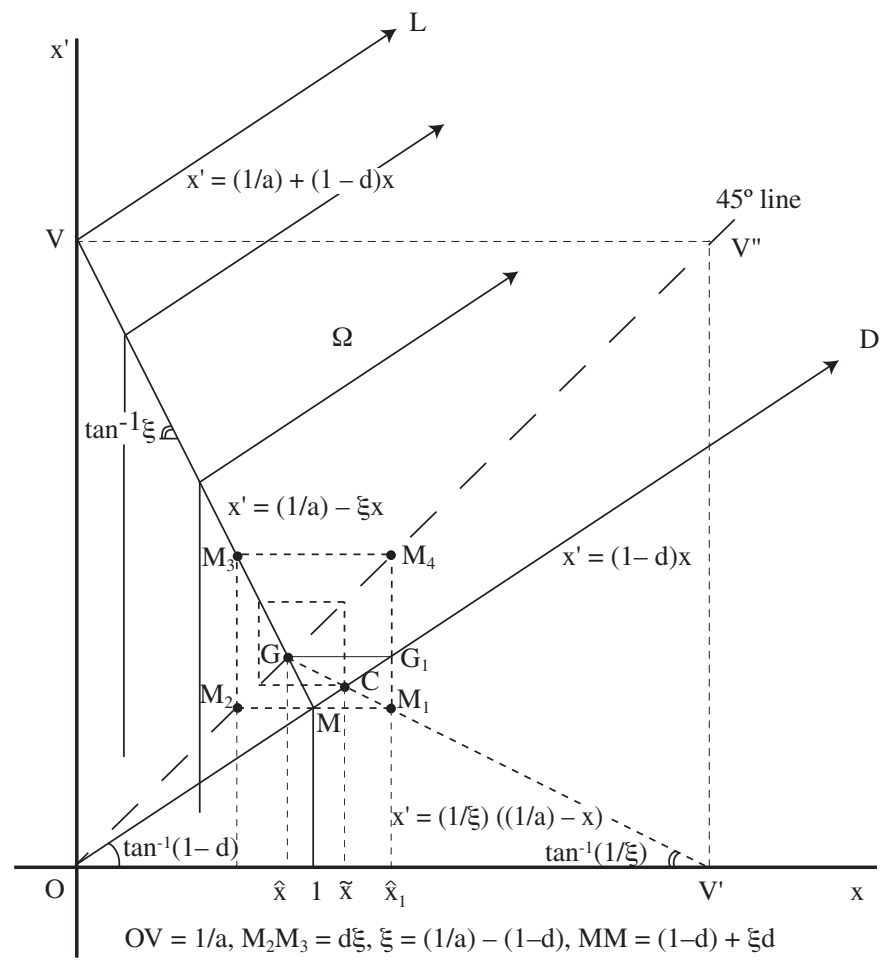

${ }^{15}$ See Khan-Mitra (2005a) for references and a detailed genealogy.

${ }^{16}$ See Ruffin-Jones (2003) for a recent use of this terminology. Such a production structure was also used by Morihiro Yomogida in his presentation at the APJAE Symposium. 
We begin with the undiscounted setting and work with the notion of a maximal program introduced in Brock (1970) and based on Atsumi-von-Weizsacker overtaking criterion. The essential ideas can be portrayed, and analyzed, in the canonical today-tomorrow diagram furnished as Figure 1. In such a diagram, the technology $\Omega$ can be represented as the open parallelogram $L V O D$, the preferences by the arrowed lines proxying an increase in felicity as one moves southeast, and the golden-rule stock by the point $G$. The fundamental point is that the $M V$ line has a triple identity: it not only serves as a hanger for the kinked indifference curves, and the locus of plans with full employment of labor and machines, but also as the locus of all plans which make zero-value losses relative to the golden-rule stock at the golden-rule prices (also referred to as Brock prices in this essay).

Once the $M V$ line is seen as an optimizing instrument imposed on a cob-web diagram, the complete characterization of optimality in the undiscounted setting follows as a consequence of Brock's 1970 theorem. ${ }^{17}$ The slope of this line, the marginal rate of transformation with zero consumption of machines from one-period to the next, $\xi=(1 / a)-(1-d)$, is the fundamental "sufficient" statistic for the model. When $\xi$ is greater than unity, as in Figure 1, the optimal policy correspondence is given by the pan-map $V G G_{1} D$. Since $M V$ is the zero value-loss line, and lines parallel to it in both directions give higher losses, the fact that all plans on $V G$ for a capital-poor economy, and all on $G_{1} D$ for a capital-rich economy, are optimal makes intuitive sense. It requires additional argument to show the optimality of all plans in the middle range $G G_{1}$, but intuition can be had from the fact that a plan on the check-map $V G M G_{1} D$ such as $C$ leads to a program that keeps on accumulating values-losses and is bad, ${ }^{18}$ leave alone optimal. Note however the implication of optimality of the pan-map: plans on the segment $V G$, perhaps reminiscent of the Gerschenkron hypothesis, require the construction of more machines than are needed in the steady state, and plans on $G G_{1}$ require construction of capital even when there is excess capacity of capital! These facts are testimonials to the hypothesis of the irreversibility of investment.

\footnotetext{
${ }^{17}$ Figure 1 shows the requirement of a unique golden-rule stock to be automatically fulfilled.

${ }^{18}$ As is well-understood by students of the theory of intertemporal resource allocation, we are using this word in a technical sense; see Brock (1970) and his reference of Gale.
} 
Figure 2: Transition Dynamics in the 2-sector RSS Model: The Case $\xi=1$

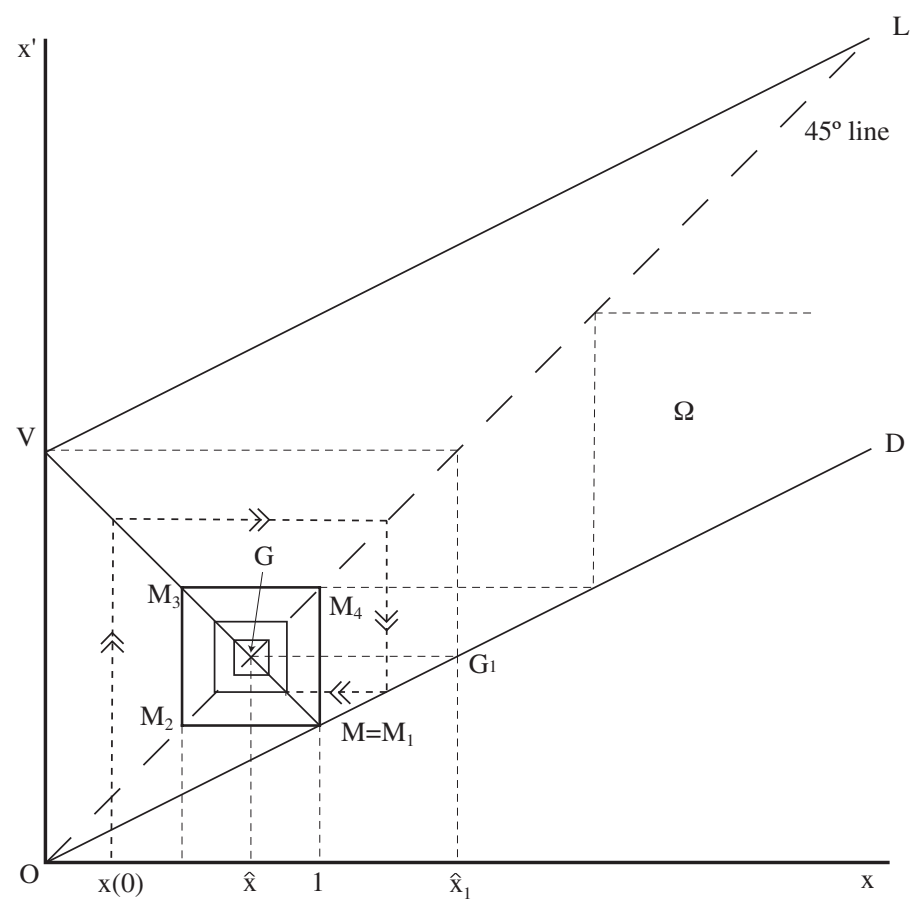

As $V$ moves towards $O$ and the $M V$ line flattens and moves counter-clockwise, the $M V$ and the $G V^{\prime}$ lines become collinear and constitute the diagonal of the square $O V V^{\prime} V^{\prime}$. As exhibited in Figure 2, in this case $\xi=1, G$ is the center of the square, the points $M, M_{1}$ and $C$ become identical, ${ }^{19}$ and a 2-period cycle from unit capital stock makes zero-value loss, and is hence optimal. What is somewhat more subtle is the indeterminacy in the optimal policy correspondence in that it now embraces the triangle $G G_{1} M$ in addition to the pan-map $V G G_{1} D$ and the check-map $V M G_{1} D$. We shall refer to this as the pan-check correspondence, and before moving to the discounted case, note that this is the only instance known to us where, in addition to an optimal program with a minimum of value-loss, as required by Brock's theorem, there is also an optimal program with a higher value-loss. ${ }^{20}$

The interesting observation about Ramsey optimality in the 2-sector RSS model in the discounted case is that the discounted or modified golden-rule stock is identical to the golden-rule stock irrespective of the discount factor, and that the transition dynamics,

${ }^{19}$ This corrects an error in Khan-Mitra (2005c; Figure 8). Figure also relies on Khan-Mitra (2005b; Figure 13).

${ }^{20}$ All the claims in this paragraph are substantiated geometrically in Khan-Mitra (2005b) and analytically, though without calculus, in Khan-Mitra (2005c). We note in passing that the first of these two papers was conceived as a "tribute to Ron Jones for his seventieth birthday." 
indeed the policy function, of the discounted case remain identical to the undiscounted case for all values of the discount factor $\rho$ between unity and $1 / \xi$. For $\rho$ less than or equal to $1 / \xi$, the transition dynamics are intricate in that, in addition to the pan- and check-maps and the pan-check correspondence, there are a variety of additional correspondences that appear "wedged in" as $\rho$ moves from $1 / \xi$ to $a$. This intricacy is a direct testimony to the Leontief kink and the corresponding irrelevance of variational calculus and the EulerLagrange conditions and to why geometry is an essential first step if one is not to be blinded by the analysis. ${ }^{21}$

\section{Jones's 2-Sector Algebra: Another Recapitulation}

We now turn to a "fuller" 2-sector model, one where machines are also used to produce machines. ${ }^{22}$ For those interested in such matters, it is of interest that there are no diagrams in Jones (1965a), and that it is in only the first four sections that concern a "small" country that takes international prices as given. The basic $A$ matrix is introduced in Section 2, and Jones notes that his "formulation serves to emphasize the dual relationship between factor endowments and commodity outputs on the one hand, and commodity prices and factor prices on the other." We shall depart from Jones's formulation only to modify the notation so that a unit of labor and $a_{I}$ machines produce $b$ machines, and with $a_{C}$ machines produce a unit of the consumption good. Then, in keeping with our assumption of a stationary unit stock of labor, and the corresponding stationary stock of machines $\hat{x}$, we obtain $^{23}$

$$
\left(\begin{array}{cc}
1 & 1 \\
a_{C} & a_{I}
\end{array}\right)\left(\begin{array}{c}
x_{C} \\
x_{I}
\end{array}\right)=\left(\begin{array}{c}
1 \\
\hat{x}
\end{array}\right) \Longrightarrow\left(\begin{array}{c}
x_{C} \\
x_{I}
\end{array}\right)=\left(\begin{array}{cc}
1 & 1 \\
a_{C} & a_{I}
\end{array}\right)^{-1}\left(\begin{array}{c}
1 \\
\hat{x}
\end{array}\right)=\frac{1}{a_{C}-a_{I}}\left(\begin{array}{c}
\hat{x}-a_{I} \\
a_{C}-\hat{x}
\end{array}\right)
$$

For balanced growth in an economy with stationary labor supply, the amount of machines produced must make up for the amount lost through depreciation, and this leads, as noted in the Jones (1965a, Section 7) to

$$
d \hat{x}=b x_{I}=b \frac{a_{C}-\hat{x}}{a_{C}-a_{I}} \Longrightarrow \hat{x}=\frac{b a_{C}}{b+d\left(a_{C}-a_{I}\right)},
$$

\footnotetext{
${ }^{21}$ A full substantiation of these claims is available in a preliminary form in Khan-Mitra (2006c). A full analysis of particular cases is available in Khan-Mitra (2005d) and Khan-Mitra (2006b).

${ }^{22}$ In a parlor game played by all who do not have a serious interest in the history of economic thought, one can inquire into the genealogy of the 2-sector model. Given the factor-intensity thrust of this essay, a playable answer would surely be Paul Samuelson's 1948-1949 papers on factor-price equalization; see Jones (1956; Section 2); also Equations 4-10 in this paper.

${ }^{23}$ This is simply a re-writing of (1)-(4) in Jones (1965a) and (1)-(2) in Jones (1965b). We follow the growth-theory literature in using "hats" to indicate equilibrium long-run variables rather than for the proportional changes well-known to Jones's followers.
} 
the formula for the golden-rule stock. ${ }^{24}$ This relationship is diagramed in Figure 3 which reproduces Figures 1 and 2 in Jones (1965b). ${ }^{25}$

Figure 3: Determination of Golden-rule Stock and Brock Prices

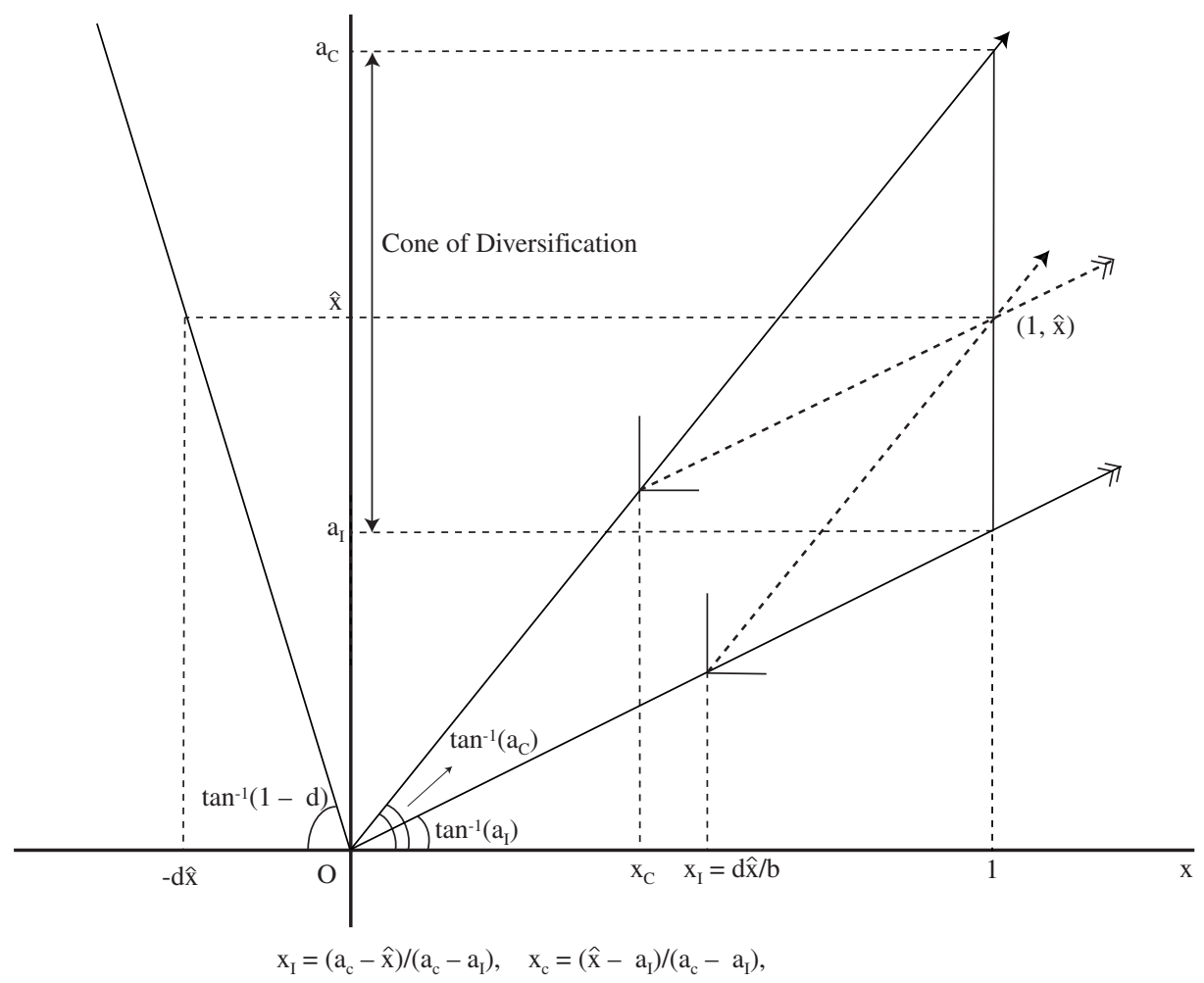

Out of balanced growth, rather than the endowments $(1, \hat{x})$, an arbitrary vector of endowments $(1, x)$, lying in the cone of diversification furnishes the marginal rate of transformation from machines this period to the amount of machines next period, $\xi=\left(b /\left(a_{C}-a_{I}\right)\right)-(1-d)$, by a consideration of the amount of machines $x^{\prime}$ that are obtained in the next period.

${ }^{24}$ We remind the reader that $x_{I}$ units of labor and $a_{I} x_{I}$ machines produce $b x_{I}$ machines.

${ }^{25}$ Figure 4 in Jones (2002) accommodates joint production. Jones (1965b) can be seen as a geometric supplement to Jones (1965a); also see Corden (1966) and Findlay (1960). Laing's (1964) geometry is perhaps the antidote intended in Jones (1965b). For two representative treatments of the 2-sector model that scrupulously avoid geometry, see Takayama (1965) and Burmeister (1968). 


$$
b x_{I}=x^{\prime}-(1-d) x \Longrightarrow x^{\prime}=(1-d) x+b\left(\frac{a_{C}}{a_{C}-a_{I}}-\frac{x}{a_{C}-a_{I}}\right)=-\zeta x+\frac{b a_{C}}{a_{C}-a_{I}} .
$$

Next, we turn to the derivation of the golden-rule or Brock prices, and the derivation of the zero-value loss line. On substituting $(1, \hat{p})$ for $(1, \hat{x})$, and $(w, r)$ for $\left(x_{C}, x_{I}\right)$ in the basic equations with which we began this section, we obtain

$$
\left(\begin{array}{cc}
1 & a_{C} \\
1 & a_{I}
\end{array}\right)\left(\begin{array}{c}
w \\
r
\end{array}\right)=\left(\begin{array}{c}
1 \\
b \hat{p}
\end{array}\right) \Longrightarrow\left(\begin{array}{c}
w \\
r
\end{array}\right)=\left(\begin{array}{cc}
1 & a_{C} \\
1 & a_{I}
\end{array}\right)^{-1}\left(\begin{array}{c}
1 \\
b \hat{p}
\end{array}\right)=\frac{1}{a_{C}-a_{I}}\left(\begin{array}{c}
b \hat{p} a_{C}-a_{I} \\
1-b \hat{p}
\end{array}\right)
$$

Note that we are now relying fully on Jones's observation as to the relationship between Rybczynski and the Stolper-Samuelson theorems. Jones (1965b) writes

"Although both propositions are well established, it seems that the dual nature of the relationship between them has never been stressed. The purpose of this chapter is to illustrate this duality feature of the basic model of trade by simple geometric means."

We can now square the circle by appealing to a Fisherian computation of the real rate of return. In a world of no discounting, which is to say a world of a zero profit rate, a dollar buys $1 / \hat{p}$ machines, produces a return of $r / \hat{p}$ from it and then sells it off for $(1-d)$, and since equilibrium requires this to yield no return, we obtain

$$
d \hat{p}=r=\left(a_{C}-b \hat{p}\right) /\left(a_{C}-a_{I}\right) \Longrightarrow \hat{p}=\left(1 /\left(b+d\left(a_{C}-a_{I}\right)\right) .\right.
$$

We can also show that the zero-value loss line is precisely the equation that we derived for the marginal rate of transformation $\zeta$. Since we are working with linear felicity functions with their coefficient normalized to unity, we obtain ${ }^{26}$

$$
\begin{aligned}
u(\hat{x}, \hat{x}) & =u\left(x, x^{\prime}\right)+\hat{p}\left(x^{\prime}-x\right) \Longrightarrow \frac{\hat{x}-a_{I}}{a_{C}-a_{I}}=\frac{x-a_{I}}{a_{C}-a_{I}}+\hat{p}\left(x^{\prime}-x\right) \\
& \Longrightarrow x^{\prime}=\frac{1-\hat{p}\left(a_{C}-a_{I}\right)}{\hat{p}\left(a_{C}-a_{I}\right)} x+\frac{\hat{x}}{\hat{p}\left(a_{C}-a_{I}\right)}=-\zeta x+\frac{b a_{C}}{a_{C}-a_{I}}
\end{aligned}
$$

Surely, the reader has wondered why, even in a celebratory paper, these 1956 formulae are being rehashed to derive known results. ${ }^{27}$ This is for three reasons. First, they give an

${ }^{26}$ Note that in contrast to the 2-sector RSS model, the reduced-form utility function $u\left(x, x^{\prime}\right)$ does not equal $x$, but rather equals $x_{C}=\left(x-a_{I}\right) /\left(a_{C}-a_{I}\right)$.

${ }^{27}$ See Fujio (2006), and also Fujio (2005a). The algebraic derivations based on Jones's matrices presented here constitute an alternative derivation of her results. 
algebraic underpinning to the claims recapitulated in Section 2 by using Jones (1965a) to derive, for that model, its golden-rule stock $\hat{x}$, its golden-rule or Brock prices $\hat{p}$, the marginal rate of transformation $\xi$ and the zero-price line. Simply equate $a_{C}$ to unity, $a_{I}$ to zero and $b$ to $1 / a$ to reduce $\xi$ to $\xi$ and to verify the formulae presented in Khan-Mitra referenced earlier. Second, it shows how easily the suggestions made in the 1956 work can be used to extend the analysis to accommodate growth and depreciation. The third reason goes deeper in its connection to Brock (1970), and to the reconciliation that constitutes the heart of this essay. We elaborate it in an independent section.

\section{Brock Prices as Analogs of International Prices}

Even a nodding familiarity with classical trade theory, say as elaborated in the texts referred to in footnote 8, lead to an appreciation of the singular position of the decomposition property known as the "factor price equalization" theorem. It is this that allows an investigation of the effect of endowment changes on outputs without having to worry about resulting changes in factor prices and corresponding changes in choice of techniques. All this is to say nothing more and nothing less than that it is this that encapsulates the "small" country assumption, and allows Rybczynski's theorem and the Jones algebra and diagrams of 1956. Once demand is made endogenous in the context of a closed economy, and neglected changes can no longer be neglected, as in sections 5 and 6 in Jones (1965a), growth and the resulting endogenous changes in capital stock, are then all cast in the context of a closed economy, as in Sections 7 to 9 in the same work. Thus, especially in the context of growth theory, two countries is indeed a large number! ${ }^{28}$

However, a less than cursory examination of the theory of intertemporal resource allocation allows us to discern at least three methodological approaches: (i) the calculus of variations and Pontryagin's maximum principle, as in Samuelson (1960) and Shell (1967 ed.), Bellman-Blackwell's dynamic programing principles, and the value-loss approach originating in Radner (1961) and brought to fruition in Brock (1970), see McKenzie (1986) for a comprehensive treatment and references. It is this third, so called dual, as opposed to the primal, approach that concerns us here. ${ }^{29}$ Under this approach, rather than the periodby-period auxiliary Pontryagin prices, or the generalized momenta of Samuelson's Hamiltonian dynamics, one works with the prices associated with the long-run steady state. Thus, the existence, and as re-emphasized by Mitra-Wan (1986), also the characterization of Ramsey optimality, hinges on minimizing the value-losses of a program relative to these Kuhn-Tucker multipliers associated with a static steady-state, and therefore static optimisation problem. It is the simple contention of this essay that these golden-rule prices,

${ }^{28}$ See, for example, Chipman-Inoue (2001) and the references therein, especially to Oniki-Uzawa; also Stiglitz (1971). However, there is a literature in growth theory associated with Harry Johnson (1971) that does take international prices as given in trade and growth context; see Eric Bond's presentation at the APJAE Symposium.

${ }^{29}$ See Khan-Mitra (1986) and their references for the problematic of the primal in the general theory of intertemporal allocation of resources. 
henceforth Brock prices, serve the precise analytical role that international trade prices serve, which is to say, break the dependence of factor price changes and choice of techniques on changes in factor endowments.

This contention can be seen through any of the canonical diagrammatic devices of trade theory, even in a world of variable coefficients but non-reversing factor intensities. In the Johnson-Meade diagram, steady-state golden-rule prices fix the wage-rental ratio, and hence national income irrespective of output changes in the vertical segment serving as the cone of diversification. The issue is "flats," and these occur in the input-output space, as in production function for foreign exchange, or in the input-input space, as in unit-value isoquants, or in the output-output space as in the transformation frontiers. ${ }^{30}$

Given the early emphasis on duality, the diagram of Woodland (1977) and Mussa (1979) ought not to remain unmentioned. In the Leontief setting, this gives rise to a "kink" instead of a "flat", but it is precisely the cone at that kink which serves as the cone of diversification - movements inside that cone do not lead to any changes in the factor prices and hence in national income.

\section{The 2-Sector Leontief Model}

It is a testimony to the influence of Jones (1965 a and b) that Section 3 can be understood without a formal specification of the 2-sector Leontief model as analyzed by Nishimura-Yano (1995a) and Fujio (2005a, 2006). ${ }^{31}$

The algebra in Section 2 was used to go back to derive benchmarks in the special case of the RSS model. Here we use it to move forward and diagram it for an analysis of the 2-sector Leontief model studied by Nishimura-Yano and Fujio (2006).

$$
\Omega=\left\{\left(x, x^{\prime}\right) \in \Re_{+} \times \Re_{+}:(1-d) x \leq x^{\prime} \leq b \min \left\{1, x / a_{I}\right\}+(1-d) x\right\},
$$

where $x$ stands for the amount of capital available now, say today, and $x^{\prime}$ the amount of capital available tomorrow. For any $\left(x, x^{\prime}\right) \in \Omega$, one can consider the amount $c$ of production of consumption goods, leading to a correspondence $\Lambda: \Omega \rightarrow \Re_{+}$with $\Lambda\left(x, x^{\prime}\right)$ equal to

$$
\left\{c \in \Re_{+}: 0 \leq c \leq \min \left\{\left(1 / a_{C}\right)\left(x-\left(a_{I} / b\right)\left(x^{\prime}-(1-d) x\right)\right), 1-(1 / b)\left(x^{\prime}-(1-d) x\right)\right\} .\right.
$$

The reduced form utility function is given as $u: \Omega \rightarrow \Re_{+}$with $u\left(x, x^{\prime}\right)=\max \{c \in$ $\left.\Lambda\left(x, x^{\prime}\right)\right\}$, representing the maximal utility level attainable today. We assume that future utility is treated equally as today's utility.

\footnotetext{
${ }^{30}$ For the first diagram, see Jones (1956) and Johnson (1957); for the second, Chipman (1971); for the third and the fourth, Jones (1974) and Jones (1961). All these diagrams are used in Jones (2002).

${ }^{31}$ Precise referencing is difficult here. Nishimura-Yano (1994, 1995b, 2000) and Fujio (2005b) also work with the 2-sector Leontieff model but with the assumption, polar opposite to that in Jones (1965a), of full depreciation, which is to say, as regime of circulating capital.
} 
Relative to the 2-sector RSS model, the 2-sector model at least doubles in its complexity, after the relevant normalizations, it is represented by the quintuple $\left(a_{C}, a_{I}, b, d, \rho\right)$ in the discounted version, and by the quadruple $\left(a_{C}, a_{I}, b, d\right)$ in the undiscounted setting, $a_{C}, a_{I}$ and $b$ being all positive numbers. As in Section 2, we begin with the undiscounted setting and work with the Atsumi-von-Weizsacker overtaking criterion. As substantiated in Fujio (2006), the essential ideas can again be portrayed, and analyzed, in the canonical today-tomorrow diagram furnished as Figures 4 and 5. The parallelism is complete except for the fact that we have now to distinguish between the labor and capital intensive cases.

Figure 4: Basic Geometrical Benchmarks of the 2-Sector Leontief Model: The Labor-intensive Case

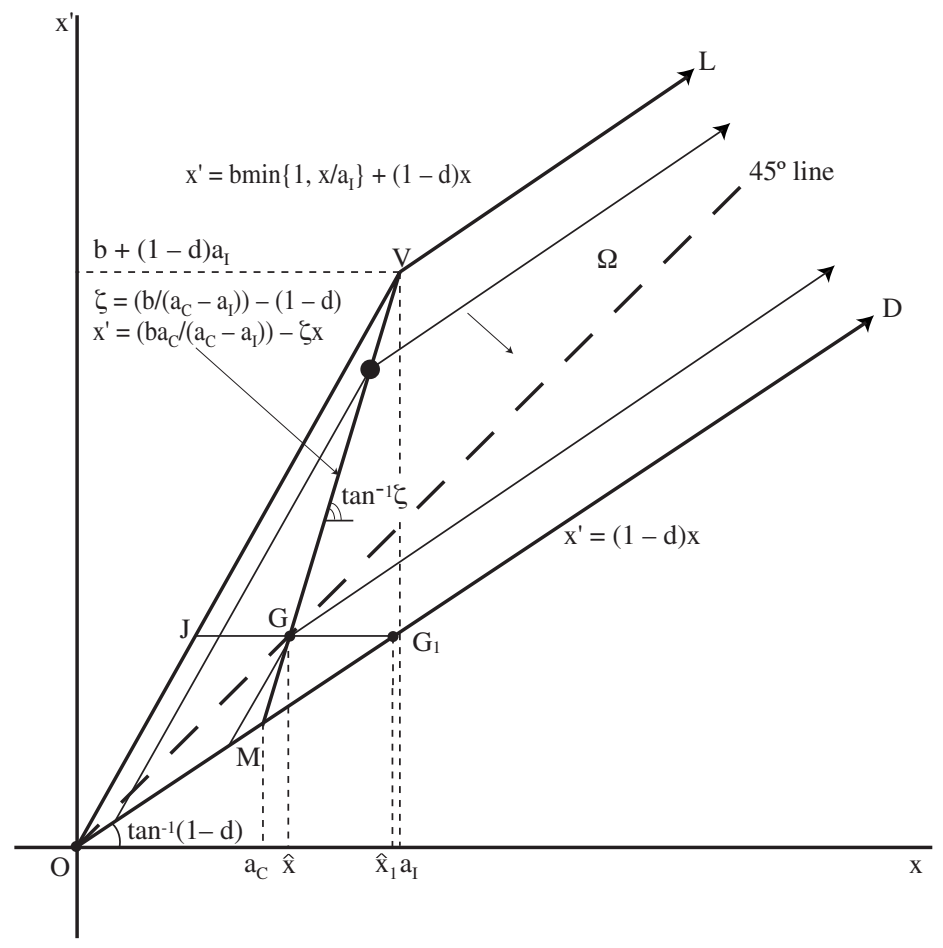

We begin with Figure 4 representing the "less-difficult" case when the investmentgoods sector is labor intensive. The interesting observation here is that a particular configuration of the parameters $\left(a_{C}, a_{I}, b, d\right)$, the $O V$ line can lie below the $45^{\circ}$-degree line to preclude the existence of a non-trivial golden-rule stock. This is the case where even a capital-rich economy is technologically too poor to sustain a non-trivial balanced growth path - the optimal policy is then to give up investment, specialize in the production of the consumption, and inevitably slide into a regimen of starvation, though in an infinite number of time periods. An existence of a unique non-trivial golden-rule stock requires the $O V$ line to be above the $45^{\circ}$-degree line, which is to say requires $b>a_{I} d$, and therefore to require that $\zeta<-1$. This leads to $G$ being an unstable source of the dynamical system with a 
subscription to full employment of resources resulting in bad programs, optimality requires that the policy function is given by the map $O J G_{1} D$. Despite its apparent similarity to the 2-sector RSS case of $\xi>1$, it needs to be emphasized that Ramsey optimality requires the jettisoning of full-employment in a capital-poor economy, the resulting monotonicity property does not happen in the RSS case (and the capital-intensive case with $\zeta>1$ discussed below).

Figure 5: Basic Geometrical Benchmarks of the 2-Sector Leontief Model: The Capital-intensive Case

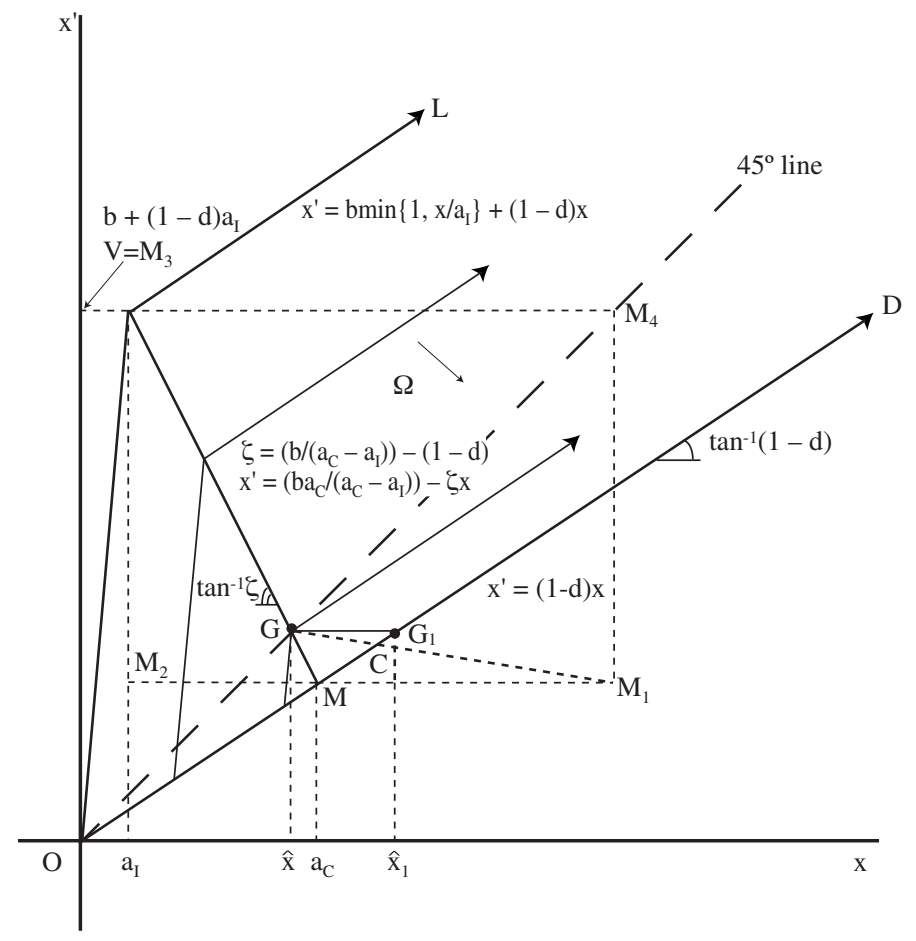

The remaining question then concerns the optimal policy correspondence with discounting. The picture suggests conjectures and their possible verification through dynamic programming or value-loss methods, but, as of now, the problem remains totally open.

Next, we turn to the capital-intensive case portrayed in Figure 5, whose comparison with Figures 1 and 2 is most instructive. One can obtain various versions of it simply by shifting the point $V$ in Figures 1 and 2 along to $M V$ line to any point above or equal to $G$ (but see the embedding result below), or to see the matter from an alternative, and antipodal, perspective, obtain various versions of Figures 1 and 2 by extending the $M V$ so that $V$ lies on the $y$-axis, or the point $a_{I}$ is shifted to the origin. This is as it ought to be, for surely the 2-sector RSS model is nothing other than a simpler, and perhaps essential, formalization of the capital-intensive case of the 2-sector Leontief model. In the former, there can be specialization to the investment-goods sector, but only for an economy which does not 
have any capital at all! ${ }^{32}$ Once there is even a minimal amount of capital stock, there is asymmetry in that the possibility of specialization is limited only the consumption-goods sector. For the undiscounted case, the shape of the optimal policy function can be tracked down through the (full-employment of resources, cone of diversification, value-loss) line and straight forward geometric manipulations relating to the cobweb diagram. As in the 2 -sector RSS case, it can shown that the optimal indeterminacy persists in the case when $\zeta$ equals unity, and that a substantial argument is called for when it is greater than unity. Again, it is only in this latter case that the discounted analysis remains totally open. ${ }^{33}$

\section{An Embedding Result}

Figures 1 and 2 illustrate an important property of the 2-sector RSS model whereby, once a plan with the square $M_{1} M_{2} M_{3} M_{4}$ is chosen, Ramsey optimality forces the planner to choices limited to the square. This square then serves as a diagramatic kernel of the RSS diagram. But there is a kernel of this kernel, and that is the trapezium $M G G_{1} M_{1}$ in Figure 1, and its degeneration to a triangle in Figure 2. In Section 2, we have already referred to the triangle $M G G_{1}$, and it is the interplay between the trapezium and the triangle, and the outside/inside distinction that it embodies, that opens the door to a complete analysis of transition dynamics in the 2-sector RSS model in the discounted setting. It is beyond the scope of this essay to report this analysis, but with it as a subtext, one can ask for conditions under which the 2-sector RSS diagram can be embedded in the 2-sector Leontief diagram. We turn to this.

\footnotetext{
${ }^{32}$ A fanciful analogy to Japan and Germany after the Second World War suggests itself.

${ }^{33}$ A full substantiation of these claims is available in Fujio (2006). Chapter 4 of this dissertation uses dynamic programming methods to show, as in the 2-sector RSS case, that the optimal policy function for the discounted and undiscounted cases remains the same for all $\rho>1 / \zeta$. However, this is only done for the case of fully circulating capital, i.e. when $d=1$ and the OD line is the $x$-axis, as in the Nishimura-Yano (1994, 1995b, 2000) papers.
} 
Figure 6: A 4-period Cycle in the 2-Sector Leontief Model: The Capital-intensive Case

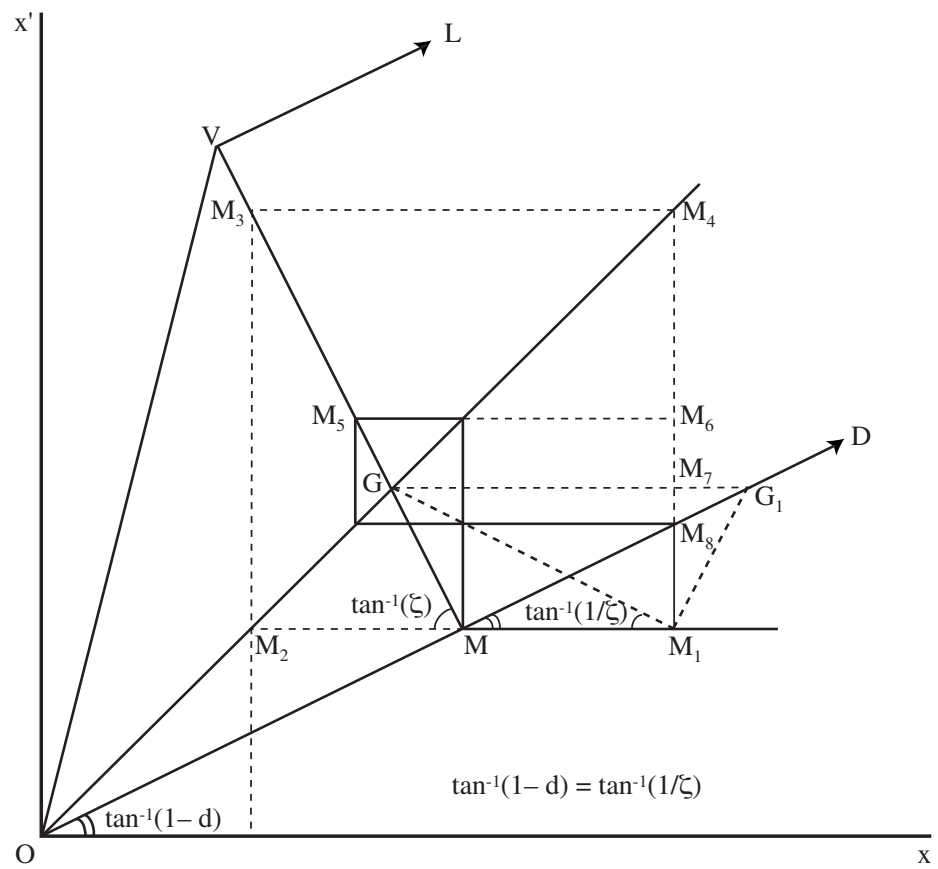

By necessity, we must consider the capital-intensive case. A simple construction reported in Khan-Mitra (2006a) allows one to derive, for a particular $\xi>1$, a value of the depreciation rate $d_{\xi}$, and a corresponding labor coefficient $a_{\xi}$ such that the check-map of the 2-sector RSS model $\left(a_{\xi}, d_{\xi}\right)$ yields an attracting 2-period cycle, a 3-period cycle, a 4-period cycle, and a program that converges to the golden-rule stock in three periods. The principal observation made here is that the construction applies verbatim to the case for a given $\xi>1$ to construct a particular version of the 2 -sector Leontief model. This is illustrated in Figures 6 and 7, all that is additionally required beyond the RSS construction is to ensure that the point $M_{3}$ lies to the right of $V$. Thus the claim is that in all these instances little is served by going beyond the 2-sector RSS setting from the viewpoint of these kinds of transition dynamics. 
Figure 7: A 3-period Cycle in the 2-Sector Leontief Model: The Capital-intensive Case

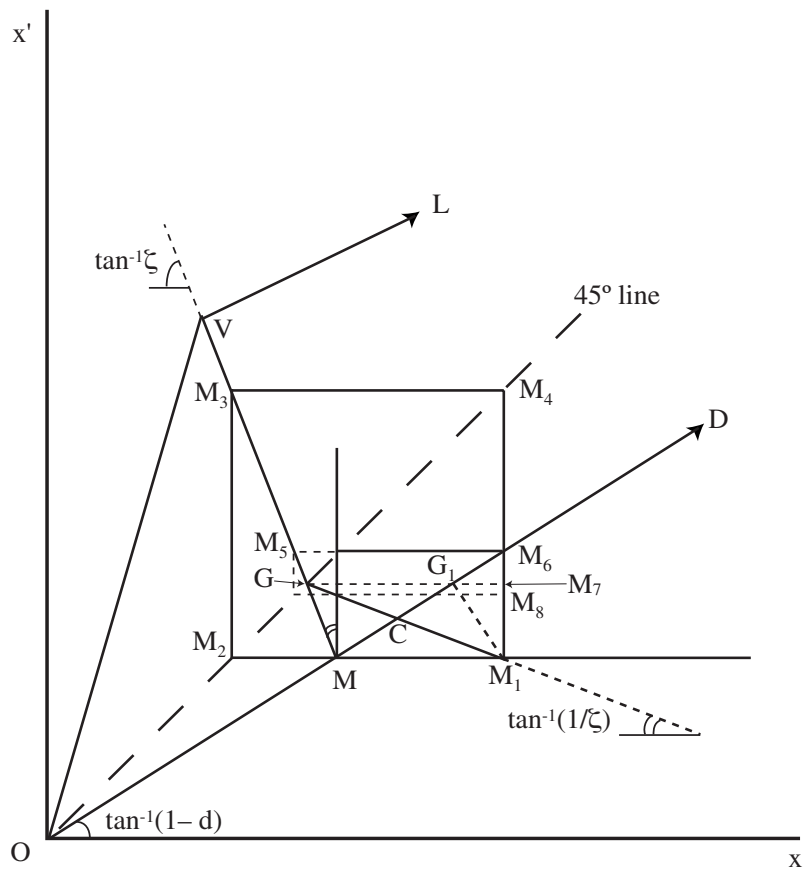

But of course the Leontief setting will give even more elaborate transition dynamics (though wonders what kind of elaborations would go beyond chaotic behavior). This will simply be the case when $M_{3}$ lies to the left of $V$ as in Figure 8. Note that this example also establishes the existence of a 2-period cycle in which it is not the intersection of the dual $M V$ line with the $O D$ line, but rather the intersection of its extension with the $O V$ line. This leads to a special kind of a 2-period cycle in which there is a continuing oscillation between specialized and unspecialized regimes, an oscillation very different from the 2-sector RSS case. ${ }^{34}$

${ }^{34}$ One may perhaps also add here that the example in Figure 7 is more (or less?) interesting than in Figure 8: in the former, full employment of labor, though not of capital, is always observed. 
Figure 8: 2- and 3-period Cycles in the 2-Sector Leontief Model: The Capital-intensive Case

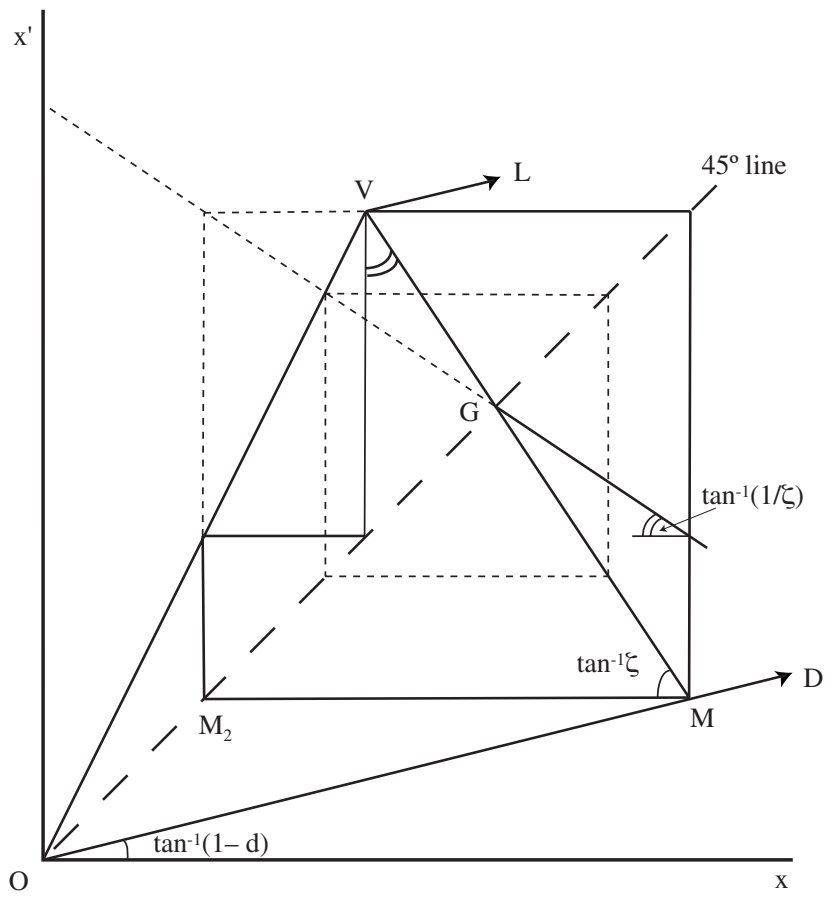

We conclude this subsection with the important observation that the RSS construction is underscored by the result reported in Khan-Mitra (2006c) that for all $\rho<a$, the checkmap is indeed optimal. Until we have a version of such a result for the Leontief case, the construction would only pertain to the undiscounted setting, and hence to bad rather than optimal programs.

\section{Concluding Remarks}

We conclude this essay by pointing to the need for the accommodation of endogenous capital accumulation in the variable coefficients (fully) neo-classical case, and to economies with distortions. Jones (1965a) uses the fixed-coefficient Leontief case simply as a first step for the fuller analysis that allows for technical substitution, an analysis further extended to distortions in Jones (1971). ${ }^{35}$ However, if this essay has been clear on one

${ }^{35}$ See Benhabib-Nishimura (1985) and footnote 27. Also, in the spirit of footnote 7, we note here Jones's resistance to the Harris-Todaro provocation despite it being seen as a simple elaboration of the HOS and Ricardo-Viner models under the direction of Jones (1971); see Khan (1985, 1987) for substantiation, and Khan-Naqvi (1983) for a presentation under the rubric of the Woodland-Mussa diagram. 
thing, it has surely been on how the simpler Leontief 2-sector case, and the even simpler 2-sector RSS case, give us the necessary guidelines along which to proceed: the cone of diversification and the resultant zero-value loss line as the crucial determinants of the policy correspondence and the resulting transition dynamics. ${ }^{36}$ Once the decomposition guaranteed by the factor-price equalization pins down the techniques, very much along the lines of intertemporal non-substitution theorems, it may only be a matter of simple elaboration. ${ }^{37}$

\section{References}

Aghion, P. and P. Howitt, 1998, Endogenous Growth Theory, (Cambridge, MIT Press). Artmann, B., 1999, Euclid - The Creation of Mathematics, (Berlin, Springer-Verlag).

Benhabib, J. and K. Nishimura, 1985, "Competitive Equilibrium Cycles", Journal of Economic Theory 935, 284-306.

Boldrin, M. and R. J. Deneckere, 1990, "Sources of Complex Dynamics in Two-Sector Growth Models", Journal of Economic Dynamics and Control 14, 627-653.

Brock, W. A., 1970, "On Existence of Weakly Maximal Programmes in a Multi-Sector Economy”, Review of Economic Studies 37, 275-280.

Brown, M. and R. W. Jones, 1962, "Economic Growth and the Theory of International Income Flows", Econometrica 30, 1-10.

Burmeister, E., 1968, "The Role of the Jacobian Determinant in the Two-Sector Model", Review of Economic Studies 9, 195-203.

Caves, R. E. and R. W. Jones, 1971, World Trade and Payments, (Boston, Little, Brown and Co., 1st edn).

Chipman, J., 1971, “The Theory of Exploitative Trade and Investment Policies: A Reformulation and a Synthesis", in L.E. di Marco (ed.), International Economics and Development (New York, Academic Press).

Chipman, J. and T. Inoue, 2001, International Comparative Advantage, University of Minnesota, mimeo.

Corden, W. M., 1966, “The Two Sector Growth Model with Fixed Coefficients", Review of Economic Studies 33, 253-262.

Ethier, W. J., E. Helpman, and J. P. Neary (eds.), 1993, Theory, Policy and Dynamics in International Trade: Essays in Honor of Ronald W. Jones, (Cambridge, Cambridge University Press).

Findlay, R., 1960, "Economic Growth and the Distributive Shares", Review of Economic Studies 27, 167-178.

\footnotetext{
${ }^{36}$ The existence of "flats" in the neoclassical case have already been mentioned above, but we ignore the issue of the "extent of factor intensity differences," emphasized in Jones (2002), and its relation to the size of the "flats" and the length of the $M V$ lines. The Haque (1970) criticism of Uzawa can perhaps be fruitfully seen under this rubric.

${ }^{37}$ See the diagram in Nishimura-Yano (1995a) regarding this point of elaboration; and Stiglitz (1970) and his references for the non-substitution theorems of Samuelson and Mirrlees.
} 
Findlay, R., 1970, Trade and Specialization, (Harmondsworth, Penguin Books).

Fujio, M., 2005a, "The Leontief Two-Sector Model and Undiscounted Optimal Growth with Irreversible Investment: The Case of Labor-Intensive Consumption Goods", Journal of Economics 86, 145-159.

Fujio, M., 2005b, "Undiscounted Optimal Growth in a Leontief Two-Sector Model with Circulating Capital: The Case of Capital-Intensive Consumption Goods Sector", Journal of Economic Behavior and Organization, forthcoming.

Fujio, M., 2006, Optimal Transition Dynamics in the Leontief Two-sector Growth Model, The Johns Hopkins University, Unpublished Ph.D. dissertation.

Hahn, F. H., 1965, “On Two-Sector Growth Models”, The Review of Economic Studies 37, 339-346.

Haque, W., 1970, “Sceptical Notes on Uzawa's 'Optimal Growth in a Two-Sector Model of Capital Accumulation', and a Precise Characterization of the Optimal Path”, The Review of Economic Studies 37, 377-394.

Johnson, H. G., 1957, "Factor Endowments, International Trade and Factor Prices", The Manchester School of Economic and Social Studies, 270-283.

Johnson, H. G., 1971, The Two-Sector Model of General Equilibrium (The Yrjö Jahnsson Lectures), (Chicago, Aldine).

Jones, R. W., 1956, "Factor Proportions and the Heckscher-Ohlin Theorem", The Review of Economic Studies 24, 1-10.

Jones, R. W., 1961, "Comparative Advantage and the Theory of Tariffs: A Multi-Country, Multi-Commodity Model”, The Review of Economic Studies 29, 161-175.

Jones, R. W., 1965a, “The Structure of Simple General Equilibrium Models", Journal of Political Economy 73, 557-572.

Jones, R. W., 1965b, "Duality in International Trade: a Geometrical Note", Canadian Journal of Economics and Political Science 31, 390-393.

Jones, R. W., 1971 "Distortions in Factor Markets and the General Equilibrium Model of Production", Journal of Political Economy 79, 437-459.

Jones, R. W., 1974, "The Small Country in a Many-Commodity World Duality in International Trade: a Geometrical Note", Australian Economic Papers 13, 225-236.

Jones, R. W., 1993, “Comments on Education as a Commodity," Pakistan Development Review 32, 580-582.

Jones, R. W., 2002, “Trade Theory and Factor Intensities: An Interpretive Essay”, Review of International Economics 10, 581-603.

Jones, R. W. and T. Mitra, 1993, "Share Ribs and Income Distribution", Review of International Economics 32, 36-52.

Jones, R. W. and T. Mitra, 1999, "Factor Shares and the Chipman Condition", in J. Melvin et al. (eds.), Trade, Welfare and Econometrics: Essays in Honor of John Chipman (New York: Routledge).

Jones, R. W., S. Marjit, and T. Mitra, 1993, “The Stolper-Samuelson Theorem: Links to Dominant Diagonals”, in Becker et al. (eds.), General Equilibrium: Growth and Trade II, (New York, Academic Press).

Jones, R. W. and J. Scheinkman, 1977, "The Relevance of the Two-Sector Production Model in Trade Theory", Journal of Political Economy 85, 909-935.

Kemp, M. C., 1969, The Pure Theory of International Trade and Investment, (Englewood Cliffs, Prentice-Hall). 
Khan, M. Ali, 1985, "On Neglected Topics in Development Economics (Quaid-E-Azam Lecture in Economic Theory)", Pakistan Development Review 27, 237-259.

Khan, M. Ali, 1987, “The Harris-Todaro Model”, in J. Eatwell et al., (eds.) The New Palgrave, (London, MacMillan).

Khan, M. Ali, 1988, "Development Policy in the Multi-Provincial Economy", Pakistan Development Review 27, 399-418.

Khan, M. Ali, 1993, "Comments on the 'New Protectionism and the Nature of World Trade"”, The Pakistan Development Review 32, 583-589.

Khan, M. Ali, 2000, "Srinivasan on Choice of Technique Again", in G. Ranis and L.K. Raut (eds.) Trade, Growth and Development: Essays in Honor of Professor T.N. Srinivasan (Amsterdam, North Holland).

Khan, M. Ali and T. Mitra, 1986, "On the Existence of a Stationary Optimal Stock for a Multi-sector Economy: A Primal Approach" Journal of Economic Theory 40, 319-328.

Khan, M. Ali and T. Mitra, 2005a, "On Choice of Technique in the RobinsonSolow-Srinivasan Model”, International Journal of Economic Theory 1, 83-109.

Khan, M. Ali and T. Mitra, 2005b, "Optimal Growth in a Two-Sector Model without Discounting: A Geometric Investigation”, Japanese Economic Review, forthcoming.

Khan, M. Ali and T. Mitra, 2005c, "Undiscounted Optimal Growth Under Irreversible Investment: a Synthesis of the Value-loss Approach and Dynamic Programming," Economic Theory, forthcoming.

Khan, M. Ali and T. Mitra, 2005d, "Discounted Optimal Growth in the Two-Sector RSS Model: A Geometric Investigation", Advances in Mathematical Economics 8, 349-381.

Khan, M. Ali and T. Mitra, 2006a, "Discounted Optimal Growth in the Two-sector RSS model: A Further Geometric Investigation", Cornell University, mimeo.

Khan, M. Ali and T. Mitra, 2006b, "The Li-Yorke Theorem and Topological Chaos in the Two-Sector RSS Model”, CAE Working Paper.

Khan, M. Ali and T. Mitra, 2006c, "Sensitivity Analysis of the Two-Sector RSS model with respect to the Discount Rate: Unpublished Notes", Cornell University, mimeo.

Khan, M. Ali and S. N. H. Naqvi, 1983 "Capital Markets and Urban Unemployment", Journal of International Economics 15, 367-385.

Kurz, M., 1970, "Review of 'The Growing Economy' by J. E. Meade”, The Journal of Finance 25, 190-193.

Laing, N. F., 1964, "A Geometrical Analysis of Some Theorems on Steady Growth", Journal of Political Economy 72, 476-482.

Liviatan, K. 1970, “A Diagramatic Exposition of Optimal Growth”, The American Economic Review 60, 302-309.

May, R. B., 1976, "Simple Mathematical Models with Very Complicated Dynamics", Nature 40, 459-467.

Majumdar, M., T. Mitra and K. Nishimura, 2000, Optimization and Chaos, Springer-Verlag, Berlin.

McKenzie, L. W., 1986, “Optimal Economic Growth, Turnpike Theorems and Comparative Dynamics", in K.J. Arrow and M. Intrilligator (eds.) Handbook of Mathematical Economics, (New York, North-Holland Publishing Company), 1281-1355. 
McKenzie, L. W., 1999, "Equilibrium, Trade and Capital Accumulation”, The Japanese Economic Review 50, 369-397.

Mitra, T. and H. Wan Jr., 1986, "On the Faustmann Solution to the Forest Management Problem", Journal of Economic Theory 40, 229-249.

Morishima, M., 1969, Theory of Economic Growth, (London, Oxford University Press).

Mussa, M., 1979, “The Two-sector Model in terms of its Dual: A Geometric Exposition", Journal of International Economics 9, 513-526.

Nishimura, K. and M. Yano, 1994, "Optimal Chaos, Nonlinearity and Feasibility Conditions", Economic Theory 4, 689-704.

Nishimura, K. and M. Yano, 1995a, "Durable Capital and Chaos in Competitive Business Cycles", Journal of Economic Behavior and Organization 27, 165-181.

Nishimura, K. and M. Yano, 1995b, "Nonlinear Dynamics and Chaos in Optimal Growth", Econometrica 7, 1941-1953.

Nishimura, K. and M. Yano, 1996, "Chaotic Solutions in Dynamic Linear Programming”, Chaos, Solitons and Fractals 7, 1941-1953.

Nishimura, K. and M. Yano, 2000, "Non-linear Dynamics and Chaos in Optimal Growth: A Constructive Exposition", in Majumdar et al., 2000, Optimization and Chaos (Berlin, Springer-Verlag).

Radner, R., 1961, "Paths of Economic Growth that are Optimal only with respect to Final States", Review of Economic Studies 28, 98-104.

Ruffin, R. J. and R. W. Jones, 2003, "Real Wages and Trade: Insights from Extreme Examples", in S. Jayasuriya (ed.), Trade Theory, Analytical Models and Development: Essays in Honour of Professor Peter Lloyd (London, Edward Elgar).

Samuelson, P. A., 1953, "Prices of Factors and Goods in General Equilibrium", Review of Economic Studies 21, 1-20.

Samuelson, P. A., 1960, "Efficient paths of Capital Accumulation in Terms of the Calculus of Variations", in K. J. Arrow, S. Karlin and P. Suppes (eds.) Mathematical Methods in the Social Sciences (Palo Alto, Stanford University Press).

Shackle, G. L. S., 1956, "Review of 'A Geometry of International Trade' by J. E. Meade”, Economica 90, 179-180.

Shell, K. (ed.), 1967, Essays on the Theory of Optimal Economic Growth (Cambridge, MIT Press).

Shinkai, Y., 1960, “On Equilibrium Growth of Capital and Labor”, International Economic Review 1, 107-111.

Solow, R. M., 1961, “Notes on Uzawa's Two-sector Model of Economic Growth”, Review of Economic Studies 29, 48-50.

Srinivasan, T. N., 1964, "Optimal Savings in a Two-Sector Model of Growth", Econometrica $32,358-373$.

Stigliz, J.E., 1970, "Non-substitution Theorems with Durable Capital Goods", Review of Economic Studies, 327, 123-137.

Stigliz, J.E., 1971, "Factor Price Equalization in a Dynamic Economy", Journal of Political Economy 78, 456-488.

Sutton, J., 1976, “The Relative factor-Intensities of Investment- and Consumer-Goods Industries", Econometrica 32, 819-821.

Takayama, A., 1965, "On a Two-Sector Model of Economic Growth - A Comparative Statics Analysis", Review of Economic Studies 32, 251-262. 
Uzawa, H., 1964, "Optimal Growth in a Two-sector Model of Capital Accumulation”, The Review of Economic Studies 31, 1-24.

Wan Jr., H. Y., 1971, Economic Growth, (New York, Harcourt Brace Jovanovich).

Woodland, A. D., 1977, “A Dual Approach to Equilibrium in the Production Sector in International Trade Theory", Canadian Journal of Economics 10, 50-68. 